\title{
Retraction
}

\section{Retraction of: „Views from the 2019 IPA African Seminar" (p. 9-25) from Notes and News, African Book Publishing Record 46-1}

https://doi.org/10.1515/abpr-2020-9020

Retraction of: „Views from the 2019 IPA African Seminar“ (p. 9-25) from Notes and News, African Book Publishing Record 46-1, (https://doi.org/10.1515/abpr-2020-0001)

The 'June 13th 2019 - Pre-Conference Events' section of the 'Review: International Publishers Association Nairobi
Seminar' article published in, Volume 46 (2020): Issue 1, was omitted without the permission of the Author. We have taken the decision to retract the article and re-publish it in full in Volume 46 (2020), Issue 3. We accept full responsibility for this error and apologise for the distress and inconvenience caused to the Author. 